Elore 1/2000, 7. vuosikerta

Julkaisija: Suomen Kansantietouden Tutkijain Seura ry., Joensuu

ISSN 1456-3010, URL: http://cc.joensuu.fi/ loristi/1_00/sep100.pdf

E-mail: loristi@cc.joensuu.fi

\title{
Veden ja vesiluonnon estetiikka
}

\section{Yrjö Sepänmaa}

Ympäristöestetiikan neljäs kansainvälinen konferenssi järjestetään Rantasalmella 14. - 17. kesäkuuta vuonna 2000. Teemana on - maiseman, metsän ja suon jälkeen - vesi. Vettä ja vesiluontoa tarkastellaan luonnontieteen, elämäntavan, taiteen ja vesiensuojelun näkökulmasta.

Kun Ilomantsissa kesällä 1998 otimme aiheeksemme suon, valitsimme syrjään jääneen ja syrjäytetyn maisemamuodon. Kiinnitimme huomiota suon, turvemaiden ja kosteikkojen esteettisiin ja niihin vaikuttaviin taloudellisiin, eettisiin ja uskomuksellisiin arvoihin - kauneusarvoihin, jotka niin usein olivat jääneet näkemättä. Eihän suo, tavallisuudestaan huolimatta, ollut päässyt itsenäisyytemme juhlavuoden 1997 tunnukseenkaan!

Esitelmöitsijät korostivat yksi toisensa perään, että suo oli kuivan maan (metsän, pellon) ja veden sijasta jotakin kolmatta ja että juuri tästä epämääräisyydestä monet suhtautumisvaikeudet juonsivat juurensa.

\section{Välittäjä vesi}

Nyt kun aiheenamme on erityisesti Itä-Suomelle luonteenomainen maisemamuoto, jonka kauneutta olemme tottuneet ylpeinä esittelemään, emme tarvitse propagandistisia puolustuspuheita: asenteet ovat valmiiksi myönteiset. Haluamme maamme nähtävän tuhansien järvien maana harmiksemme Kanadan Ontarion ja Puolan kanssa samasta iskulauseesta kilpaillen.

Välimaailmoissa liikumme silti edelleen. Kirjalla, jonka nimi on yksinkertaisesti Water ('Vesi'), on alaotsikko 'Worlds between Heaven and Earth' eli 'Taivaan ja maan väliset maailmat'. Vesiluonto on todellakin välimaailmoja - monikossa, koska esimerkiksi makean ja suolaisen veden ekosysteemit ovat niin erilaisia.

Taivaan ja maan väliset vesimaailmat ovat puhdaspiirteinen kolmas vaihtoehto. Sellainen ne ovat toisella tapaa kuin suo, joka on maan ja veden sekoitusta - ja tämän sekoituksen eri muodoilla on kovin erilaisia nimiä: räme, neva, korpi, letto, aapa. Vesiluonto, niin kuin suokin ja mikä tahansa kosteikko, voidaan poistaa kuivattamalla tai sellainen voidaan saada aikaan patoamalla.

Veteen liittyy vapaa-aikamme veneily, kalastus, mökkeily, saunominen. Veden ja vesistöjen ehdoilla kaupunkimme ovat löytäneet kasvualustansa; ensimmäiset kulkureittimme ovat vesiteitä. Vesivoima pyörittää turbiineita vieläkin. Vesi on tietysti elämämme neste: ruumiimme on aivan 
sananmukaisesti suurimmaksi osaksi vettä. Vesi on kulttuurimme uskomusten ja uskontojen kannattaja.

Veden oma olomuoto on kiehtovan moninainen. Nesteenä se on vailla ominaisuuksia: hajutonta, mautonta, läpikuultavaa. Hyvän juomaveden ominaisuudet ovat positiivisesti luonnehdittuina puhtaus, kirkkaus ja raikkaus. Tällaista hyvää vettä on vain yhdenlaista, ja on kaupallisuuden ihme, että kivennäisvesistä pystytään kehittämään merkkituotteita "Vesissä on eroa" -mainoslauseen mukaisesti. Erot ovat mainoksilla synnytetyissä mielikuvissa, tai sitten ne ovat yksinkertaisesti maustamalla aikaansaatuja todellisia eroja. Maailmalla, jo Tukholmassa, on erityisiä vesibaareja.

Joidenkin lähteiden vesi on niin arvostettua juomavetenä, että sitä kannattaa rahdata pullotettuna valtameren yli (ranskalaista Perrieriä Amerikkaan ja kanadalaista Clearly Canadiania Eurooppaan). Terveyslähteiden varaan on perustettu kuuluisia kylpylöitä. Vedellä on näissä tapauksissa ominaisuuksia: todettu, mutta aisteille näkymätön parantava tai ainakin virkistävä vaikutus. Täysin puhdas tislattu vesi on lähtökohta, ja ominaisuudet synnytetään lisäaineilla; sellaisenaan se on hyvää kyllä auton akussa.

Harvoin ajattelemme vettä kaikkien sen olomuotojen kokonaisuutena: jää on jäätä, sumu sumua, lumi lunta, höyry höyryä. Tiedämme ja aistimme tietysti joka päivä tämän veden muutosihmeen. Pesu- ja kylpyvetenä vesi on miellyttävintä ruumiinlämpöisenä, saunassa nautimme lauhkeasta löylystä, mutta myös kirpaisevasta kuumuudesta, aurinkoisena kesäpäivänä kaipaamme jäistä juomavettä. Odotuksemme vaihtelevat tilanteen ja tarpeittemme mukaan.

\section{Vesimaisema}

Vesi maisemassa on pitkälti samalla tavalla ominaisuudeton, mutta siinä se lainaa kärkkäästi sivusta ja siksi se kaiken aikaa muuntuu ympäristönsä mukaan kuin Woody Allenin elokuvan Zelig. Vaikka vesi sinänsä on väritöntä, se ei maisemassa ole sellaista: välillä se on taivaansinistä, välillä yönmustaa, välillä savipeltojen ja likavesien harmauttamaa. Poutapäivinä ja tyynellä säällä se kuvastaa maisemia. Vesi on kielemme mukaan "maiseman peili", järveä puhutellaan "maiseman kasvoiksi" ja lähteellä on saman logiikan mukaan "silmä". Voiko tästä päätellä, että vesi olisi yhtä arvokas kuin silmäterä? Kieleemme on rakentunut se viisaus, jonka nykyinen ekologia samoin kuin yhteiskuntatieteet ovat nostaneet esiin.

Maisemassa veden liike kiehtoo mieltä. Sen solina ja välke rauhoittavat. Virtaava vesi on ihailtu luonnonelementti, ja se on tuotu keinotekoisiin vesiputouksiin ja suihkulähteisiin. Las Vegasin Bellagio-hotellin edustan tekolammessa vesi tanssii musiikin tahdissa: pinnanalaiset urkupillistöt puhaltavat tiheän vesiverhon, joka välillä liehuu ja lepattaa keveästi, välillä ryhdistäytyy kurinalaisen sotilaallisesti liikkuvaksi vesirintamaksi Riverdancen tapaan.

\section{Veden voima}

Yhtä aikaa vesi on elementti, joka tarjoaa viatonta huvia ja virkistystä, mutta on toisena hetkenä valmis tulvillaan ja myrskytessään hukuttamaan vesille uskaltautuneen. Vaikka padoilla ja muilla järjestelyillä tätä käyttäytymistä otetaan hallintaan, ei siinä olla läheskään onnistuttu.

Kosket, putoukset, lähteet ja virranpyörteet ovat paikkoja, joita kokoonnutaan ihastelemaan. Mutta ne ovat myös paikkoja, jotka selittämättömällä tavalla vetävät puoleensa. Imatra ja Niagara ovat vetäneet tuhoon herkkiä mieliä; ne ovat imu kuin Hitchcockin Vertigo. 
Kansanperinteessämme elää hiisi tai näkki, joka houkuttelee äkkisyvään. Vesi on tietysti vaarallinen myrskytessä, tulviessa, jäisen kylmänä ja polttavan kuumana, tyynenäkin voimansa väärin arvioivalle uimarille.

Veden voima ei ole turhaa puhetta. Koskien patoaminen vain kasvattaa voimaa; ihminen ottaa virtauksen voiman käyttöön valjastamalla - tällaista hevoskulttuurin kieltä vielä käytämme. Pelkkä liike, putousvoima, tuottaa sähköä ja pyörittää myllyjä; höyrykoneen keksiminen oli merkittävimpiä teollisen vallankumouksen tekijöitä. Mutta veden vahvuus ilmenee myös sen taidossa käyttä työvälineitä - hiekkaa ja irtokiviä - ja taidossa muuntaa olomuotoa kuin kauhuelokuvien hirviö: unohdamme helposti, että vesi käy läpi ikuista kiertokulkuaan, jossa sen määrä pysyy samana, vain olomuodot ja paikka vaihtelevat.

\section{Vesi ja rakentaminen}

Mannerjään liike on kovertanut kallioperään järvemme; veden virtaus on kasannut harjumme hiekasta, sorasta ja irtokivistä. Muotoilijana vesi toimii hioessaan hiidenkirnuja ja siloittaessaan rantakallioita. Vesi itse on näin suurelta osin muovannut vesiluonnon maisematekijät: järvialtaat, joenuomat.

Luonnontilainen vesiluonto on esteettiseltä kannalta valmis ihailun ja arvostuksen kohde, ja siinä meitä opettavat niin kirjalliset luonnonkuvaajat kuin valokuvaajatkin. Vesiluonnon rakentaminen taas on ympäristön tekijöille esteettinen haaste. Tehtävät ulottuvat suihkulähteiden, patojen, puhdistuslaitosten, ojitusten ja kuivatusten suunnittelusta todella suuriin ympäristöhankkeisiin: tekoaltaisiin ja jokien kääntämiseen. Mitä suurempi muutos, sitä välttämättömämmin siihen liittyy myös tekemisen oikeutuksen eettinen arviointi.

\section{Kirjallisuutta}

Furo \& sauna. Päätoimittaja Esa Laaksonen. Arkkitehti 5 - 6 B, 1997 \& Hashi 19/1997.

Gelt, Joe: “Fountains - Water Wasters or Works of Art?” - Arroyo, April 1993.

Giblett, Rodney James: Postmodern Wetlands. Culture, History, Ecology. Postmodern Theory, Series editor: Thomas Docherty. Edinburgh University Press, Edinburgh 1996.

Jokiranta, Rita: Seascape stories. Stockholm 1996.

van Leeuwen, Thomas A.P.: The Springboard in the Pond. An Intimate History of the Swimming Pool. Edited by Helen Searing. The MIT Press, Cambridge, Massachusetts, London, England, 1998.

Litton, R. Burton, Jr., Tetlow, Robert J., Sorensen, Jens, Beatty, Russell A.: Water and Landscape. An aesthetic overview of the role of water in the landscape. Water Information Center, Inc., Port Washington, N.Y., 1974.

Oinonen, Yrjö: Vesiluonto Eino Leinon ajan runoudessa. Kouvola 1945.

Tinsley, Jim Bob: The Land of Waterfalls. Transylvania County, North Carolina. Published by Jim Bob and Dottie Tinsley, Brevard, N.C., 1988. 
Vesiraja 4,8 m. Valokuvia Vuotoksesta. Kuvat Mikko Junninen, teksti Suonna Kononen. Kustannus Pohjoinen, Oulu 1995.

Waterproof: 150 Years of Water in Photography. Ed. by Jorge Calado. Edition Stemmle 1998.

Rezendes, Paul, Roy, Paulette: Wetlands. The Web of Life. A Sierra Club Book, San Francisco 1996.

Wolfe, Art (photographs), Gilders, Michelle A. \& Biegert, Claus (text): Water: Worlds Between Heaven and Earth. Stewart Tabori \& Chang, New York 1999.

Prof. Yrjö Sepänmaa

Joensuun yliopisto

Suomen kielen ja kulttuuritieteiden laitos

yrjo.sepanmaa@joensuu.fi 